\title{
The Effect of Angiogenesis Inhibitor TNP-470 against Postoperative Lung Metastasis following Removal of Orthotopic Transplanted Human Colon Cancer: An Experimental Study
}

\author{
HITOSHI ODA, YUTAKA OGATA AND KAZUO SHIROUZU \\ Department of Surgery, Kurume University School of Medicine, \\ Kurume 830-0011, Japan
}

\begin{abstract}
Summary: We have investigated the antimetastatic effect of TNP-470 against postoperative lung metastasis following the removal of human colon cancer xenotransplanted into nude rat. The KM12SM human colon cells were injected into the cecal wall. At 5 weeks after the injection, the cecum was removed including the tumor. Then, TNP-470 was administered continuously by subcutaneous injection pump at a dosage of $30 \mathrm{mg} / \mathrm{kg} /$ week. The Control Group received no administration of TNP-470. Group A and Group B received administration of TNP-470 just after the cecal removal for 4 and 2 weeks, respectively. Group C received 2 weeks' administration of TNP-470 from week 3 after the removal. The survival rate of each group was calculated, and any lung metastasis was evaluated macro and microscopically. At 7 weeks after the removal, lung metastasis was detected in all rats of the Control Group, and in 4 of 8 rats in Group C. In Groups A and Group B, only one rat developed lung metastasis. The 30 week-survival rate in Group A and that in Group B was significantly higher than that in the Control Group or Group C. Moreover, the incidence of lung metastasis at the time of death or 30 weeks after the removal in Group A, and in Group B, was lower than that in Control Group or Group C. The angiogenesis inhibitor, TNP-470 showed an excellent antimetastatic effect against postoperative lung metastasis from transplanted human colon cancer.
\end{abstract}

Key words preclinical lung metastasis model, angiogenesis inhibitor, TNP-470, colon cancer, orthotopic transplantation

\section{INTRODUCTION}

Most patients with colorectal cancer have a good prognosis. However, liver or lung metastasis might occur in some patients even if a curative operation is performed. It is thought that the existence of micrometastasis already established prior to operation in correlated with the rapid development of postoperative liver or lung metastasis. Therefore, to improve the postoperative prognosis for patients with colorectal cancer, effective adjuvant therapy against present micrometastasis should be considered. It has been shown that solid tumor growth beyond a certain size requires neovascularization to supply the tumor with oxygen and nutrients [1]. In other words, without neovascularization, micrometastasis cannot continue to grow. Therefore, it has been suggested that antiangiogenesis therapy is effective against various solid tumors by inhibiting neovascularization [1-4].

Recently, the angiogenic inhibitor, TNP-470 isolated from Aspergillus fumigatus, a synthetic analog of fumagillin, has been a focus of new attention because of its antiproliferative or antimetastatic effect [3-13]. However, the effect on postoperative lung metastasis is obscure because it is extremely difficult to establish an adequate animal model of the lung 
metastasis. We have previously reported [14] that we succeeded in establishing an ideal animal model inducing lung metastasis by transplanting KM12SM cells originally from human colon cancer [15] into nude rat. In the present study, we also succeeded in establishing an animal model involving radical removal of human colon cancer after transplantation into the nude rat. Here, we investigated the in vivo antimetastatic effect of TNP-470 against postoperative lung metastasis following the curative removal of the human colon cancer, after orthotopic transplantation using KM12SM cells into the cecum of the nude rats.

\section{MATERIALS AND METHODS}

\section{KM12SM cells}

A KM12SM human colon carcinoma cell line was kindly provided by Dr. Motowo Nakajima (Novartis Pharma K.K., Tsukuba, Japan). These cells have special characteristics inducing only spontaneous lung metastases without liver metastasis by the transplantation into the cecum in nude rat [14]. As shown in Fig. 1, no liver metastasis was demonstrated even at autopsy.

\section{TNP-470}

TNP-470 (AGM-1470), which is a synthetic analog of fumagillin, was generously provided by Takeda Chemical Industries (Osaka, Japan). It was suspended in a vehicle composed of $1 \%$ ethanol plus $5 \%$ gum arabic in saline. The concentration of TNP470 was controlled by RPMI-1640 medium supplemented with $10 \%$ heat-inactivated fetal calf serum (FCS, GibcoBRL, Grand Island, NY) following solubilazation in dimethylsulfoxide.

\section{In vitro cell growth inhibition}

The KM12SM cells were seeded at a density of $1 \times 10^{5}$ into the 25 -cm 2 culture flasks containing $5 \mathrm{ml}$ RPMI-1640 medium supplemented with 10\% FCS and incubated overnight to allow cell attachment. The next day, TNP-470 was added to the cultures at various concentrations; divided into 7 groups as follows i.e., control, $10 \mu \mathrm{g} / \mathrm{ml}, 1 \mu \mathrm{g} / \mathrm{ml}, 100 \mathrm{ng} / \mathrm{ml}, 50$ $\mathrm{ng} / \mathrm{ml}, 25 \mathrm{ng} / \mathrm{ml}$, and $10 \mathrm{ng} / \mathrm{ml}$. On day 2, 4, and day 6 , the medium was replaced with the RPMI-1640 containing TNP-470. On day $1,3,5$, and day 7 , the morphology of the KM12SM cells was examined microscopically. Viable tumor cells were determined by the trypan blue exclusion test, and the number of viable tumor cells was counted.

\section{In vivo inhibitory effects of TNP-470}

Animals: Male F344n-rnu/rnu rats, aged 4 weeks, were purchased from CLEA Japan Inc (Tokyo, Japan). The rats were maintained in a laminar-flow cabinet under specific pathogen-free conditions and were used for experiments when they were five weeks old. The rats were maintained in facilities in accordance with the regulations and standards of the a)

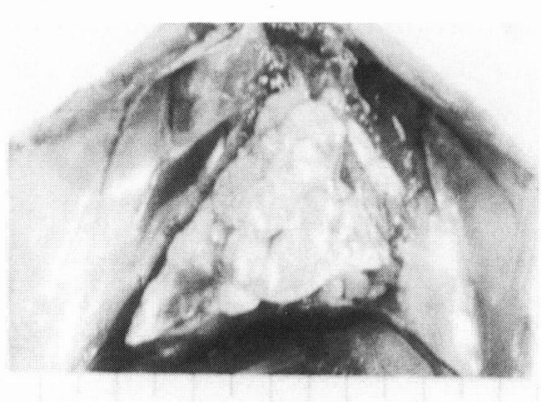

b)

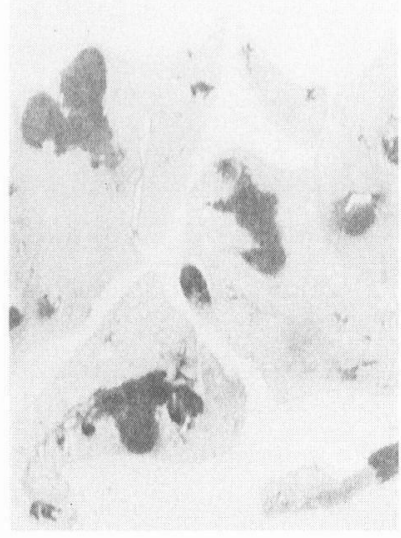

c)

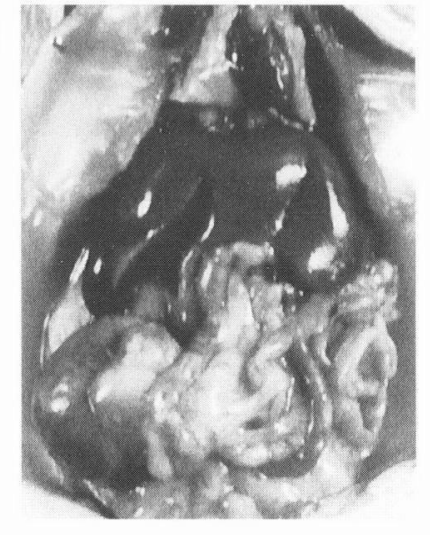

Fig. 1. Characteristics of the KM12SM human colon carcinoma cells. The KM12SM cells have specific characteristics inducing only spontaneous lung metastasis without liver metastasis by the transplantation into the cecum in nude rats. The gross (a) and histological (b) findings showed multiple lung metastases, and no liver metastasis and no peritoneal dissemination (c). 
Kurume University School of Medicine.

Cancer cell line: KM12SM cells were used for transplantation into the cecum of the rat. These cells were maintained in a culture of RPMI-1640 supplemented with $10 \%$ FCS in a humidified $5 \% \quad \mathrm{CO}_{2}$ atmosphere. The tumor cells were harvested from subconfluent cultures produced by 30 -second treatment with tripsin-EDTA (GibcoBRL, Grand Island, NY). The dislodged cells were first washed in RPMI1640 supplemented with 10\% FCS, and then resuspended in PBS (Nissui Inc, Tokyo, Japan) for injection. Only single-cell suspensions $\left(1 \times 10^{8} / \mathrm{ml}\right)$ with greater than $90 \%$ viability were used for the injections.

Orthotopic transplantation of KM12SM cells and removal of cecal tumor (Curative resection model): Each rat was anesthetized with ether, and the abdomen prepared for sterile surgery. A small abdominal incision was made, and the cecum was exteriorized. Viable tumor cells $\left(2 \times 10^{6}\right.$ cells $/ 0.02 \mathrm{ml}$ PBS) were injected into the cecal wall from the serosal side using a 30-gauge needle (Fig. 2a). The cecum was returned to the abdominal cavity, and the wound was closed using 3-0 Vicryl surgical sutures (Ethicon Inc, Somervill, NJ). At 5 weeks after transplantation, the rat was anesthetized and operated on as described above, and the cecum with a growing tumor was exteriorized. After confirming that the tumor size was larger than $1 \mathrm{~cm}$ in greatest diameter, the cecum including the lymph nodes in the mesoappendix was carefully removed using an Endopath Endocutter (Ethicon Endo-Surgery Inc, Cincinnati, $\mathrm{OH})$, as shown in Fig. 2b. After removal of the cecum, the wound was closed again using 3-0 Vicryl surgical sutures.

Administration of TNP-470: Each rat in the Control Group received the vehicle only (1\% ethanol plus 5\% gum arabic in saline). Each rat in each treated group received subcutaneous injection of TNP-470 at a dosage of $30 \mathrm{mg} / \mathrm{kg} /$ week continuously using an Alzet pump (ALZA Co., CA) emplaced in the ileolumbar subcutis (Fig. 2c). There were 3 treated groups according to the schedule of the TNP-470 administration as shown in Fig. 3. Group A received

(b)
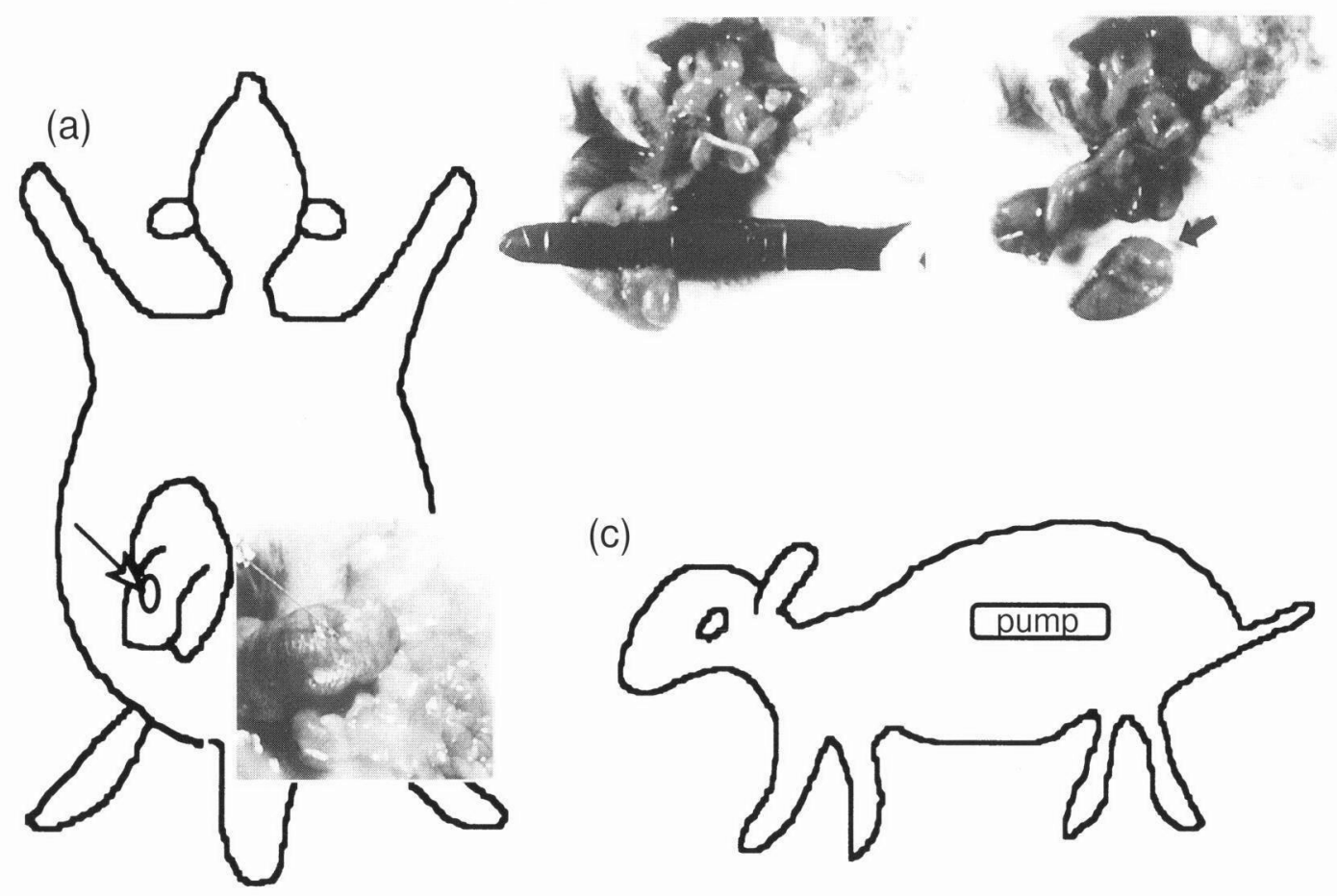

(c)

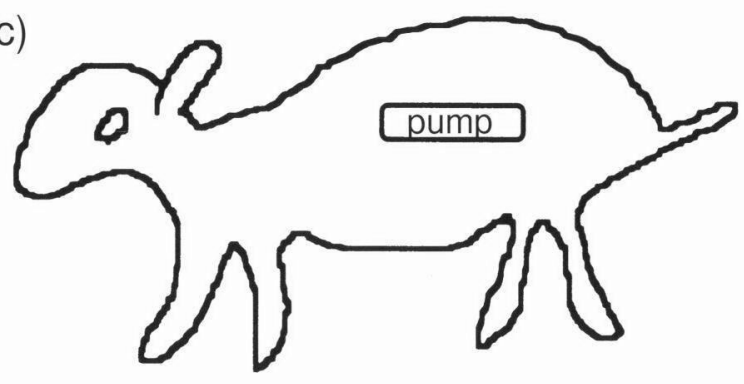

Fig. 2. Methods of tumor transplantation, removal of the cecum, and emplacement of osmotic pump for TNP-470 administration. The KM12SM human colon carcinoma cells were injected into the subserosa of the cecal wall using a 30-gauge needle (a). At 5 weeks after the transplantation, the cecum including the growing tumor was removed using an Endopath Endocutter (b). An osmotic pump (Alzet pump) was emplaced into the ileolumbar subcutis of the rat (c). 
4 weeks' administration from immediately after the removal of the cecum, Group B received 2 weeks' administration from immediately after the cecal removal, and Group C received 2 weeks' administration from week 3 after the cecal removal.

Assay of the tumor growth and metastasis: The rats were sacrificed and autopsied at 7 weeks after the removal of the cecum or at the time of death. Any recurrent tumor, if present, was also removed, and the lung, liver, and lymph nodes were weighed and processed for histological examination. The extent of lung metastasis was divided into three degrees; as two plus $(++)$ for metastasis recognized macroscopically, as one plus $(+)$ for metastasis detected only microscopically, or as minus $(-)$ for no metastasis.

Assay of the survival: Long-term survival was assessed between 7 and 30 weeks after the removal of the cecum to evaluate the effect on survival of the TNP-470 administration. All rats were autopsied at the time of death or at thirty weeks after the removal of the cecum, and a histological examination was performed as described above.

\section{Statistical analysis}

All data were analyzed by the use of the $\chi^{2}$ test and Fisher's test and student's two-tailed t-test. The Kaplan-Meier method was used to calculate survival rates; and any significant difference in rates was assessed using the Logrank test. A p-value less than 0.05 was considered statistically significant.

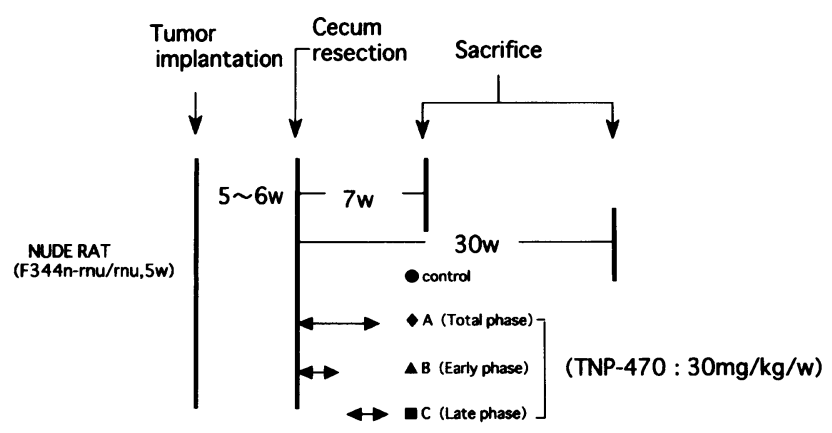

Fig. 3. Schedule of the administration of TNP470. At 5 weeks after transplantation, the cecum was removed including the tumor. Then, TNP-470 was administered at a dosage of $30 \mathrm{mg} / \mathrm{kg} /$ week . Administration was divided into 4 groups. The Control Group received no administration of TNP470. Group A received 4 weeks' administration just after the removal of the cecum tumor, Group B received 2 weeks' administration just after the removal, and Group C received 2 weeks' administration from week 3 after the removal.

\section{RESULTS}

In vitro cell growth inhibition against KM12SM cells by $T N P-470$

Growth of the KM12SM cells was inhibited at concentrations of TNP-470 equal to or higher than 25 $\mathrm{ng} / \mathrm{ml}$ of TNP-470 (Fig. 4). Change in the cytoplasm, breakdown in the cell membrane and/or shrinkage in the nuclei was observed at the highest concentration of $1 \mu \mathrm{g} / \mathrm{ml}$ TNP-470 (data not shown), and so the cell toxicity level was determined to be equal to or higher than a concentration of $1 \mu \mathrm{g} / \mathrm{ml}$.

\section{Serial change of the lung metastasis}

The histological examination of the lung metastasis at autopsy at 2 weeks after the removal of the cecum with transplanted tumor showed microtumor emboli inside capillaries. Also, emboli invaded to outside the capillary with destruction in the elastic fiber and induction of stromal tissue including neovascularization (Fig. 5a,b). In other words, micrometastasis was histologically confirmed. At 3 weeks after the removal, multiple lung micrometastases was confirmed (Fig. 5c). At 5 weeks after the removal, the nodules of micrometastasis were also detectable macroscopically due to their growth in size (Fig. 5d).

Inhibitory effect on lung metastasis and on local recurrence by TNP-470 administration

At 7 weeks after the removal of the cecum, lung metastasis was found in all rats in the Control Group

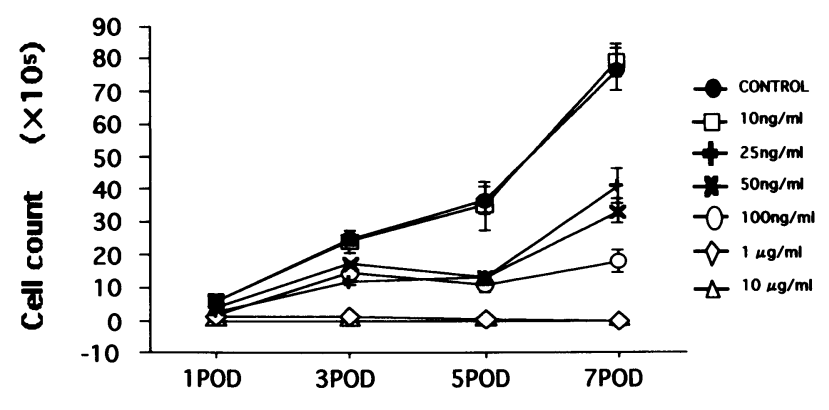

Fig. 4. In vitro cell growth inhibition against KM12SM cells by TNP-470. The TNP-470 was added to the cultures of KM12SM cells at various concentrations being divided into 7 groups as follows i.e., $10 \mu \mathrm{g} / \mathrm{ml}, 1 \mu \mathrm{g} / \mathrm{ml}, 100 \mathrm{ng} / \mathrm{ml}, 50 \mathrm{ng} / \mathrm{ml}, 25$ $\mathrm{ng} / \mathrm{ml}, 10 \mathrm{ng} / \mathrm{ml}$ groups and control group). The growth of the KM12SM cells was inhibited at higher than or equal concentration to $25 \mathrm{ng} / \mathrm{ml}$ of TNP-470. 
a)

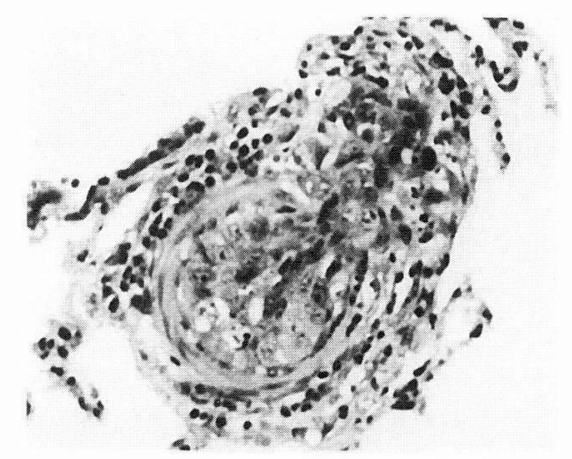

$(\mathrm{H} . \mathrm{E} \times 200)$

c)

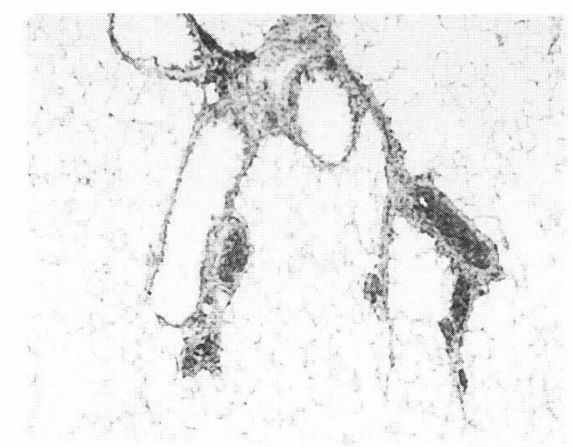

$(H . E \times 100)$ b)

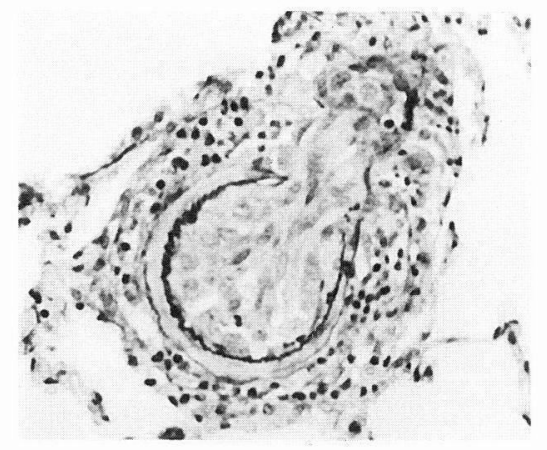

$(E V G \times 200)$

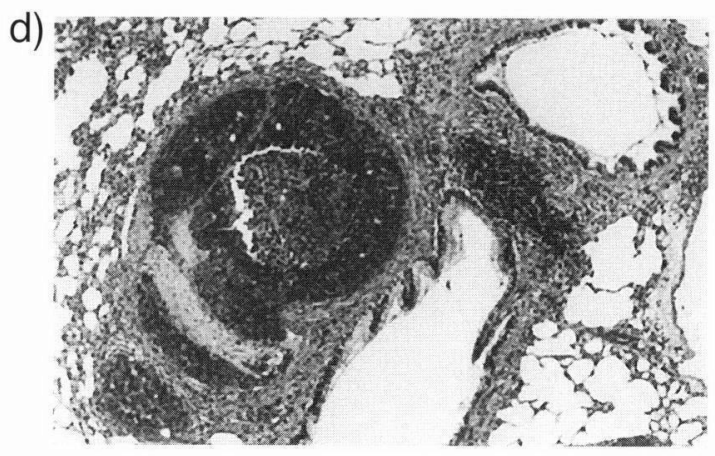

$($ H.E $\times 100)$

Fig. 5. Microscopic findings of the lung metastasis. Histological findings of the lung metastasis at autopsy at 2 weeks after the removal of the cecum with transplanted tumor showed micro tumor emboli inside the capillary. Also, the emboli invaded beyond the capillary with destruction in elastic fiber, and accompanied with an induction in stromal tissue including neovascularization ( $\mathrm{a}$ and $\mathrm{b}$ ). At 3 weeks after the removal, multiple lung micrometastases appeared (c). At 5 weeks after the removal, each nodule of micrometastasis was detected macroscopically due to increasing size (d).

TABLE 1.

The effects of TNP-470 on metastatic potentials and lung weights at 7 weeks after resection of cecal tumor in orthotopically inoculated colon carcinoma in nude rats

\begin{tabular}{ccccccc}
\hline Group & \multicolumn{3}{c}{ Lung meta. } & $\begin{array}{c}\text { Liver meta. } \\
(+)\end{array}$ & $\begin{array}{c}\text { Local recurrence } \\
(+)\end{array}$ & $\begin{array}{c}\text { Wet weight of lung (mg) } \\
\text { mean } \pm(\mathrm{SD})\end{array}$ \\
\cline { 2 - 5 } $\begin{array}{c}\text { Control } \\
\mathrm{n}=10\end{array}$ & 0 & 3 & 7 & 0 & 8 & $1288 \pm 181$ \\
$\begin{array}{c}\text { Group A } \\
\mathrm{n}=8\end{array}$ & 8 & 0 & $0^{\mathrm{a}}$ & 0 & $1^{\mathrm{d}}$ & $1129 \pm 60^{\mathrm{e}}$ \\
$\begin{array}{c}\text { Group B } \\
\mathrm{n}=10\end{array}$ & 9 & 1 & $0^{\mathrm{b}}$ & 0 & 3 & $1153 \pm 850$ \\
$\begin{array}{c}\text { Group C } \\
\mathrm{n}=8\end{array}$ & 4 & 2 & $2^{\mathrm{c}}$ & 0 & 4 & $1288 \pm 344$ \\
\hline
\end{tabular}

a: $p=0.0001 ; b: p=0.0002 ; c: p=0.0327 ; d: p=0.0078$; $: p=0.0399$ (The $p$ values were compared to the Control.)

(Fig. 6a,b). In contrast, lung metastasis was strongly suppressed in Group A or in Group B receiving early administration of TNP-470 after the removal of the cecum, with no metastasis detected macroscopically (Fig. 6c). The suppression effect on lung metastasis was only slight, however, in Group C receiving late administration of TNP-470 from 2 weeks after the removal, at which time neovascularization had already become induced into the micrometastasis (Fig. 6d). The wet weight of the lung at autopsy in 
a)

b)
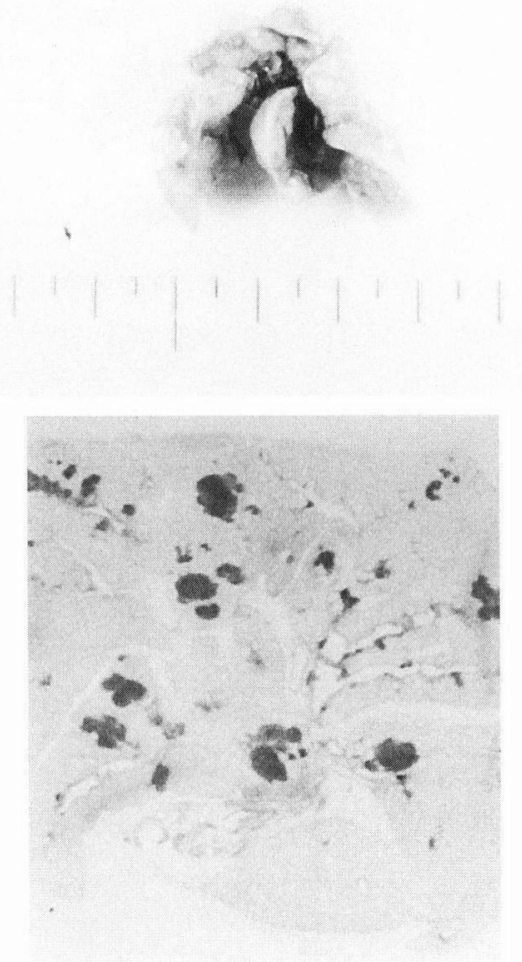

c)

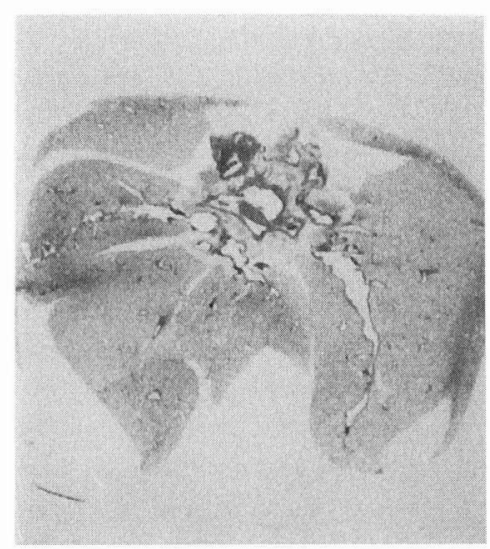

d)

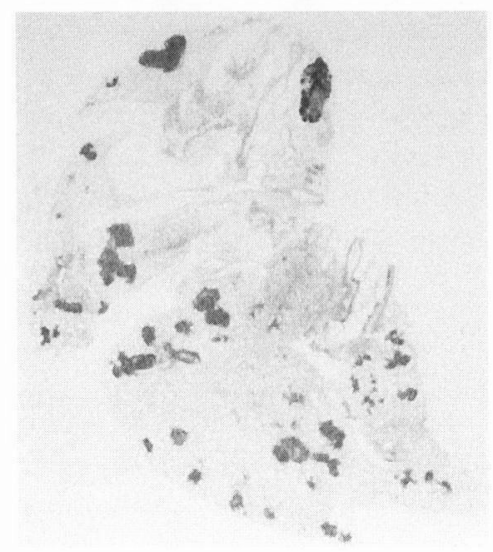

Fig. 6. Suppression effect on lung metastasis. Lung metastasis was found in all rats macroscopically (a) or microscopically (b) in the Control Group (a and b). However, the lung metastasis was almost completely suppressed in Group A and in Group B receiving early administration of TNP-470 after removal of the cecum. No lung metastasis was found microscopically (c). The suppression effect on lung metastasis was extremely slight in Group C receiving late administration of $\mathrm{TNP}-470$ (d).

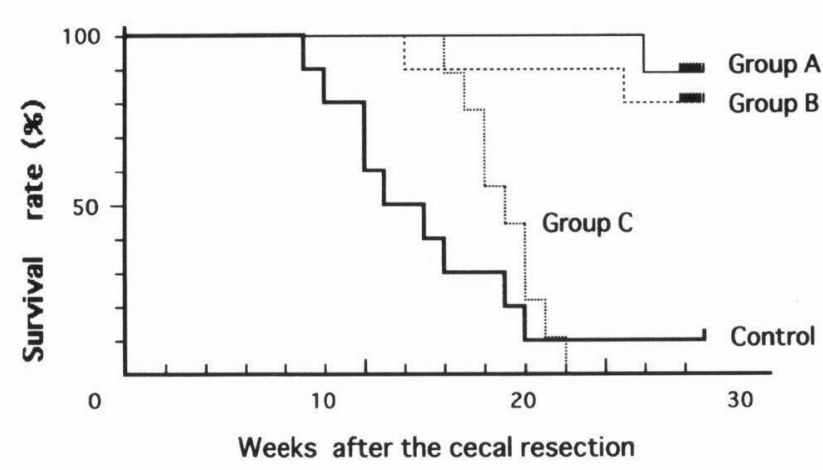

Fig. 7. Survival curves after the cecal resection. The 30-week-survival rate was significantly higher in Group A and in Group B compared with that in the Control Group and Group C ( $\mathrm{p}<0.05)$.

Group A was significantly higher than that in the Control Group (Table 1). Moreover, the local recurrence rate in the abdominal cavity in Group A was significantly lower than in the Control Group.

Weight loss in the rat

There was no significant difference among the groups concerning the weight loss, - an adverse-effect of TNP-470 (data not shown).

Survival and recurrence after the removal of cecal tumor

The 30-week survival rate was significantly higher in Group A and in Group B compared with that in the Control Group or Group C (Fig. 7). The lung metastasis at the time of the death during follow-up or at 30 weeks after the cecal removal was significantly suppressed in Group A and in Group B compared with the Control Group. There was no lung metastasis in any rat with 30-week survival in either Group A or Group B. No significant difference in the local recurrence rates was found among all groups (Table 2). 
TABLE 2

The effects of TNP-470 on metastatic potentials at the time of death or at 30 weeks after resection of cecal tumor

\begin{tabular}{cccc}
\hline Group & $\begin{array}{c}\text { Lung meta. }(+) \\
(\%)\end{array}$ & $\begin{array}{c}\text { Liver meta. }(+) \\
(\%)\end{array}$ & $\begin{array}{c}\text { Local recurrence (+) } \\
(\%)\end{array}$ \\
\hline Control & 9 & 0 & 6 \\
$\mathrm{n}=10$ & $(90)$ & & $(60)$ \\
Group A & $1^{\mathrm{a}}$ & 0 & 2 \\
$\mathrm{n}=9$ & $(11)$ & & $(22)$ \\
Group B & $2^{\mathrm{b}}$ & 0 & 3 \\
$\mathrm{n}=10$ & $(20)$ & & $(30)$ \\
Group C & 7 & 0 & 6 \\
$\mathrm{n}=9$ & $(78)$ & & $(67)$ \\
\hline
\end{tabular}

$\mathrm{a}: \mathrm{p}=0.0011 ; \mathrm{b}: \mathrm{p}=0.0055$ (The $\mathrm{p}$ values were compared to the Control.)

\section{DISCUSSION}

A good animal experimental model similar to human cancer is needed to judge the effects and establish clinical postoperative adjuvant therapy. Our orthotopic transplantation model was thought to be an ideal animal model similar to a clinical study, because the KM12SM cells were originally from human colon cancer [15] and had the special characteristics that induced only spontaneous lung metastases by the orthotopic transplantation into the cecum in nude rats [14]. Therefore, the tumor cells were able to proliferate actively in the microenvironment similar to that of original organ, and various metastatic processes were included from the growth in the primary lesion to the implantation and proliferation in the target organ, and hematogenous metastasis or local lymph node recurrence developed as in human cancer. The process of the establishment of hematogenous metastasis is complex, and has been previously described [16]. Recently, interest has been concentrated on the role of neovascularization required for any proliferation in the metastatic lesion [1,17-19]. Neovascularization is required to deliver a supply of nutrients, oxygen, and various proliferation factors if neovascularization develops, then the tumor cells are able to continue proliferating and the tumor mass is formed. Moreover, neovascularization is not only indispensable to tumor growth, but also an important factor delivering biological malignancy, which promotes hematogenous or lymphatic metastasis.

In conventional anti-cancer drug chemotherapy in which cancer cells are targeted, the characteristics of cancer cells are various and so drug sensitivity is not uniform, cancer cells are able to acquire drug resistance easily, and anti-cancer drugs show strong toxicity to normal cells. Therefore, it is difficult to achieve sufficient impact only from conventional anti-cancer drugs. Since neovascularization is indispensable for tumor growth, suppressing the neovascularization could be an effective mode for cancer treatment. It has been reported that neovascularization is not usually observed in adult human physiologically except for in the genital organs, and that the turnover time of endothelial cells in proliferation in the tumor blood vessels is remarkably short, as short as that of bone marrow cells [20]. Therefore, if a strong angiogenic inhibitor is used in a new cancer treatment, it will show high specificity to impeding tumor growth and have few if any side effects. It seems worthwhile to target the neovascularization of the tumor as a cancer therapy. In fact, it has recently been reported that TNP-470 showed anti-proliferation and anti-metastasis effects by its inhibitory action against neovascularization even in vivo using transplanted human tumors [4-13].

The authors examined mainly the effect of TNP470 on the micro pulmonary metastasis by using the removal model of the orthotopic transplanted colorectal cancer. The early continuous subcutaneous injection of TNP-470 was able to inhibit the development of lung metastasis almost completely after the removal of the transplanted tumor (Group A or Group B). However, the suppression effect was negligible in Group $\mathrm{C}$ after stromal tissue had been induced around the metastatic lesion at which time neovacularization had already become developed. Also of interest, was the obtained disappearance and cure of micrometastasis from TNP-470 starving the microlesion by stopping neovascularization: the survival in Group A and Group B was significantly higher than that in the Control Group or Group C, and there was no metastasis whatsoever in rats with long term survival. This is the condition expected most from postoperative adjuvant therapy preventing recurrence.

From our morphological observation of small changes in the cytoplasm, breakdown in the cell membrane and/or shrinkage in the nuclei, the cytotoxicity of TNP-470 on the KM12SM cells was determined to occur at a concentration of at least 1 $\mu \mathrm{g} / \mathrm{ml}$. With regard to the effects of the TNP-470 on the vascular endothelial cells, the concentration at which vascular endothelial cells proliferation is inhibited is considered to be at about $1 / 100$ of the 
concentration at which cell toxicity is caused [21,22]. Pharmacokinetic analysis of TNP-470 using rhesus monkeys showed that TNP-470 was undetectable in the plasma and the only metabolic byproducts were present in plasma as early as 6 min after intravenous administration of $5 \mathrm{mg} / \mathrm{kg}$, suggesting a rapid and extensive metabolism of TNP-470 [23]. Therefore, the present reduction in the lung metastasis was thought to be secondary to the angioinhibitory activity of TNP-470 in the rat rather than cytotoxic activity on the KM12SM cells.

To investigate the anti-tumor mechanisms including anti-angiogenic activity of TNP-470 in our model, we have compared cancer cell necrosis, apoptotic index, and the Ki-67 labeling index in macroscopically detectable lung tumors, and found there was no difference in these parameters between the rats treated with TNP-470 and the vehicle (data not shown). These findings could have been due to the long interval between the end of the administration of TNP-470 and the time of our evaluation of the parameters, during which time the tumors treated with TNP-470 had grown to become the same size as the control tumors treated with vehicle. We also have not yet examined and not yet demonstrated direct evidence of inhibition on initial neovascularization in preclinical lung metastases, because most of the tumors sensitive for TNP-470 (Group A or Group B) had disappeared and were cured.

Local recurrence was inhibited by the long-term early administration of TNP-470 (Group A), though this suppression effect on local recurrence was not observed with short-term early administration (Group B). Although it was difficult to clarify the mode of local recurrence macroscopically and histologically, lymph node recurrence in the mesocecum was suspected. As to the lymph node recurrence (local recurrence), the relationship between the beginning of neovascularization in a local recurrence lesion and the suppression effect of TNP-470 against the neovascularization could not be adequately clarified in this study. There seems to be a difference in the suppression effect of the angiogenic inhibitor between the hematogenous metastasis and lymph node metastasis, perhaps due to a difference in time needed for their respective initial neovascularizations.

We concluded that the strong effect of TNP-470 even with short-term early administration on the metastasis suppression was due to inhibiting the initial neovascularization of the tumor at the early stage of metastasis, when neovascular networks had not yet been formed. If the neovascular network becomes already formed in some microlesions, then the antitumor effect of TNP-470 will need to be reinforced by combined other chemotherapy drugs.

ACKNOWLEDGMENTS: This work was supported in part by a Grant-in-Aid for Scientific Research (C) (No. 10671231) from the Ministry of Education, Culture, Sports, Science and Technology of Japan.

\section{REFERENCES}

1. Folkman J. What is the evidence that tumors are angiogenesis dependent? J Natl Cancer Inst 1990; 82:4-6.

2. Ingber D, Fujita T, Kishimoto S, Sudo K, Kanamaru T et al. Synthetic analogues of fumagillin that inhibit angiogenesis and suppress tumor growth. Nature 1990; 348:555-557.

3. Ahmed MH, Arai T, Konno H, Nahar L, Tanaka T et al Regression of metastatic liver tumors in rats treated with angiogenesis inhibitor TNP-470: occurrence of apoptosis and necrosis. Jpn J Cancer Res 1997; 88:977-981.

4. Tanaka T, Konno H, Matsuda I, Nakamura S, and Baba $\mathrm{S}$. Prevention of hepatic metastasis of human colon cancer by angiogenesis inhibitor TNP-470. Cancer Res 1995; 55:836-839.

5. Yanase T, Tamura M, Fujita K, Kodama S, and Tanaka K. Inhibitory effect of angiogenesis inhibitor TNP-470 on tumor growth and metastasis of human cell lines in vitro and in vivo. Cancer Res 1993; 53:2566-2570.

6. Castronovo V, and Belotti D. TNP-470 (AGM-1470): mechanisms of action and early clinical development. Eur J Cancer 1996; 32A:2520-2527.

7. Ishikawa H, Satoh H, Kamma H, Naito T, Ohtsuka M et al. The effect of TNP-470 on cell proliferation and urokinase-type plasminogen activator and its inhibitor in human lung cancer cells lines. J Exp Ther Oncol 1996; 1:390-396.

8. Ikebe T, Yamamoto T, Kubo S, Hirohashi K, Kinoshita $\mathrm{H}$ et al. Suppressive effect of the angiogenesis inhibitor TNP-470 on the development of carcinogen-induced hepatic nodules in rats. Jpn J Cancer Res 1998; 89:143149.

9. Kanai T, Konno H, Tanaka T, Matsumoto K, Baba M et al. Effect of angiogenesis inhibitor TNP-470 on the progression of human gastric cancer xenotransplanted into nude mice. Int J Cancer 1997; 71:838-841.

10. Satoh $H$, Ishikawa $H$, Fujimoto $M$, Fujiwara $M$, Yamashita $\mathrm{Y}$ et al. Angiocytotoxic therapy in human non-small cell lung cancer cell lines. Acta Oncol 1998; 37:85-90.

11. Konno H, Tanaka T, Kanai T, Maruyama K, Nakamura S et al. Efficacy of an angiogenesis inhibitor, TNP-470, in xenotransplanted human colorectal cancer with high metastatic potential. Cancer 1996; 77:1736-1740.

12. Konno K, Tanaka T, Matsuda I, Kanai T, Maruo Y et al Comparison of the inhibitory effect of the angiogenesis inhibitor, TNP-470, and mitomycin C on the growth and 
liver metastasis of human colon cancer. Int $\mathbf{J}$ Cancer 1995; 61:268-271.

13. Yamaoka M, Yamamoto $T$, Ikeyama $S$, Sudo $K$, and Fujita T. Angiogenesis inhibitor TNP-470 (AGM-1470) potently inhibits the tumor growth of hormone-independent human breast and prostate carcinoma cell lines. Cancer Res 1993; 53:5233-5236.

14. Hara Y, Ogata Y, and Shirouzu K. Early tumor growth in metastatic organs influenced by the microenvironment is an important factor which provides organ specificity of colon cancer metastasis. J Exp Clin Cancer Res 2000; 19:497-504.

15. Morikawa K, Walker SM, Nakajima M, Pathak S, Jessup $\mathrm{JM}$ et al. Influence of organ environment on the growth, selection, and metastasis of human colon carcinoma cells in nude mice. Cancer Res 1988; 48:6863-6871.

16. Poste G, and Fidler IJ. The pathogenesis of cancer metastasis. Nature 1980; 283:139-146.

17. Folkman J, Watson K, Ingber D, and Hanahan D. Induction of angiogenesis during the transition from hyperplasia to neoplasia. Nature 1989; 339:58-61.

18. Liotta L, Kleinerman J, and Saldel G. Quantitative rela- tionships of intravascular tumor cells, tumor vessels, and pulmonary metastases following tumor implantation. Cancer Res 1974; 34:997-1004.

19. Starky JR, Crowle PK, and Taubenberger S. Mast-celldeficient $\mathrm{W} / \mathrm{W}$ mice exhibit a decreased rate of tumor angiogenesis. Int J Cancer 1988; 42:48-52.

20. Folkman J. Clinical application of research on angiogenesis. N Engl J Med 1995; 333:1757-1763.

21. Kusaka M, Sudo K, Matsutani E, Kozai Y, Marui S et al. Cytostatic inhibition of endothelial cell growth by the angiogenesis inhibitor TNP-470. (AGM-1470). Br J Cancer 1994; 69:212-216.

22. Yamamoto T, Sudo K, and Fujita T. Significant inhibition of endothelial cell growth in tumor vasculature by an angiogenesis inhibitor, TNP-470 (AGM-1470). Anticancer Research 1994; 14:1-3.

23. Cretton-Scott E, Placidi L, McClure H, Anderson DC, and Sommadossi JP. Pharmacokinetics and metabolism of O-(chloroacetyl-carbamoyl) fumagillol (TNP-470, AGM-1470) in rhesus monkeys. Cancer Chemother Pharmacol 1996; 38:117-122. 